\title{
17. PROCESSES OF CRYSTALLIZATION IN PILLOW BASALTS, HOLE 396B, DSDP LEG 46
}

\author{
R. James Kirkpatrick, ${ }^{1}$ Scripps Institution of Oceanography, La Jolla, California
}

\section{INTRODUCTION}

Ocean floor basalt pillows are among the most rapidly cooled igneous bodies on earth and offer an important opportunity to study the effects that rapid cooling rates have on the textural and mineralogical features of basalts. Many of the features of pillow basalts have been described by Bryan (1972), but in general they have not received the extensive study to which lunar basalts have been subjected (Dowty et al., 1974; Lofgren et al., 1975; Walker et al., 1976, and many others). The purpose of this paper is to describe the groundmass petrographic features of pillow basalts recovered on Leg 46 of Glomar Challenger and to examine the origin of these features in the light of recent advances in our understanding of the rates and mechanisms of the processes which occur during the crystallization of igneous rocks.

The samples are from DSDP Hole 396B located about $160 \mathrm{~km}$ east of the Mid-Atlantic Ridge at $22^{\circ} 59.14^{\prime} \mathrm{N}$, $43^{\circ} 30.90^{\prime} \mathrm{W}$. The overall results of the drilling and geologic setting have been presented by the Leg 46 Scientific Staff (this volume). The oldest sediment recovered at this site is middle Miocene (about 13 m.y.).

The pillows examined come from the sparsely phyric pillow sequence (lithologic Units 1 and 2) and from the porphyritic pillow sequence (lithologic Unit 4). For the sparsely phyric pillows only glassy pillow rinds up to about $8 \mathrm{~cm}$ long were recovered. For the porphyritic pillows, rinds and one complete pillow about $45 \mathrm{~cm}$ thick were available.

This paper will first describe the petrographic variation observed in the pillows, then briefly review some of the aspects of the theory of crystallization kinetics necessary to explain the variation, and finally discuss the petrography in the light of this theory.

\section{PETROGRAPHY OF THE PILLOWS}

Although the main petrographic distinction between the basalts recovered on Leg 46 is based on phenocryst content (porphyritic versus sparsely phyric), the groundmass textural variation depends primarily on whether or not there is significant groundmass olivine. Those pillows with significant groundmass olivine are always sparsely phyric, while those with little groundmass olivine can be either porphyritic or sparsely phyric. Table 1 lists the samples examined.

There are, of course, many similarities between the two types of pillows, and the variation in both is in good agreement with theoretical prediction. Both pillow types are made of basalt of oceanic tholeiite (Kay et al., 1970) composition; both have phenocrysts of olivine and plagioclase

'Present Address: Department of Geology, University of Illinois, Urbana, Illinois, 61801
TABLE 1

Samples Examined

\begin{tabular}{cc}
\hline $\begin{array}{c}\text { Groundmass } \\
\text { Olivine-Rich } \\
\text { (All Sparsely Phyric) }\end{array}$ & \multicolumn{1}{c}{$\begin{array}{c}\text { Groundmass } \\
\text { Olivine-Poor }\end{array}$} \\
\hline $7-1,10-14 \mathrm{~cm}$ & $5-1,163-167 \mathrm{~cm}$ Sparsely phyric \\
$8-1,113-122 \mathrm{~cm}$ & $7-2,42-47 \mathrm{~cm}$ Sparsely phyric \\
$10-1,64-69 \mathrm{~cm}$ & $16-2,125-133 \mathrm{~cm}$ Porphyritic \\
$11-2,36-40 \mathrm{~cm}$ & $17-3,50-60 \mathrm{~cm}$ Porphyritic \\
$13-1,89-93 \mathrm{~cm}$ & $20-1,36-80 \mathrm{~cm}$ Porphyritic \\
$15-1,37-44 \mathrm{~cm}$ & $20-4,3-5 \mathrm{~cm}$ Porphyritic \\
\hline
\end{tabular}

only; and the groundmass phases of both are plagioclase, augitic clinopyroxene, olivine, titanomagnetite, sulfide spherules, and residual glass. Both also contain clearly recognizable petrographic zones, similar to those described by Bryan (1972), which parallel the pillow margins. The gross variation from glassy margin to microlitic interior is also the same for both. In detail, however, the variation is different.

In the groundmass of olivine-rich pillows six textural zones can be recognized. From the margin inward these are (1) glass; (2) glass with isolated olivine dendrites and plagioclase spherulites; (3) coalesced olivine dendrites and partially coalesced plagioclase spherulites with residual glass between; (4) fully coalesced plagioclase spherulites with distinct spherulite boundaries; (5) fully coalesced bow-tie shaped plagioclase spherulites with indistinct spherulite boundaries; (6) microlitic plagioclase with dendritic pyroxene between. Figure 1 illustrates this variation.

Of the samples observed, Zone 1, the glass zone, occurs only in Sample 8-1, 113-122 cm, where it is $3 \mathrm{~mm}$ thick. Very likely the zone was originally present in all pillows, but because the glass is so brittle, it was lost during cooling or during the drilling process. The only crystals present in this zone are a few skeletal or euhedral plagioclase and olivine grains about $0.07 \mathrm{~mm}$ long, some of which occur in clusters that contain a number of both olivine and plagioclase individuals, and are very similar to some of the crystals that core plagioclase spherulites further into the pillow. They probably formed before or during eruption. There are no spherulitic or dendritic overgrowths on these crystals in this zone. Rounded sulfide blebs a few $\mu \mathrm{m}$ across occur in this and all other zones.

Zone 2, the isolated olivine dendrite and plagioclase spherulite zone, occurs in all pillow margin samples examined and is about $4 \mathrm{~mm}$ thick. The olivine dendrites in this zone (Figure 2) are very similar to those illustrated by Bryan (1972) and range from about $0.2 \mathrm{~mm}$ in diameter at the outside of the zone to about $0.4 \mathrm{~mm}$ inside. Many of the dendrites have a non-dendritic olivine center which is optically continuous with the dendrite. The size of and spacing between the dendrite fibers decrease continually outward 

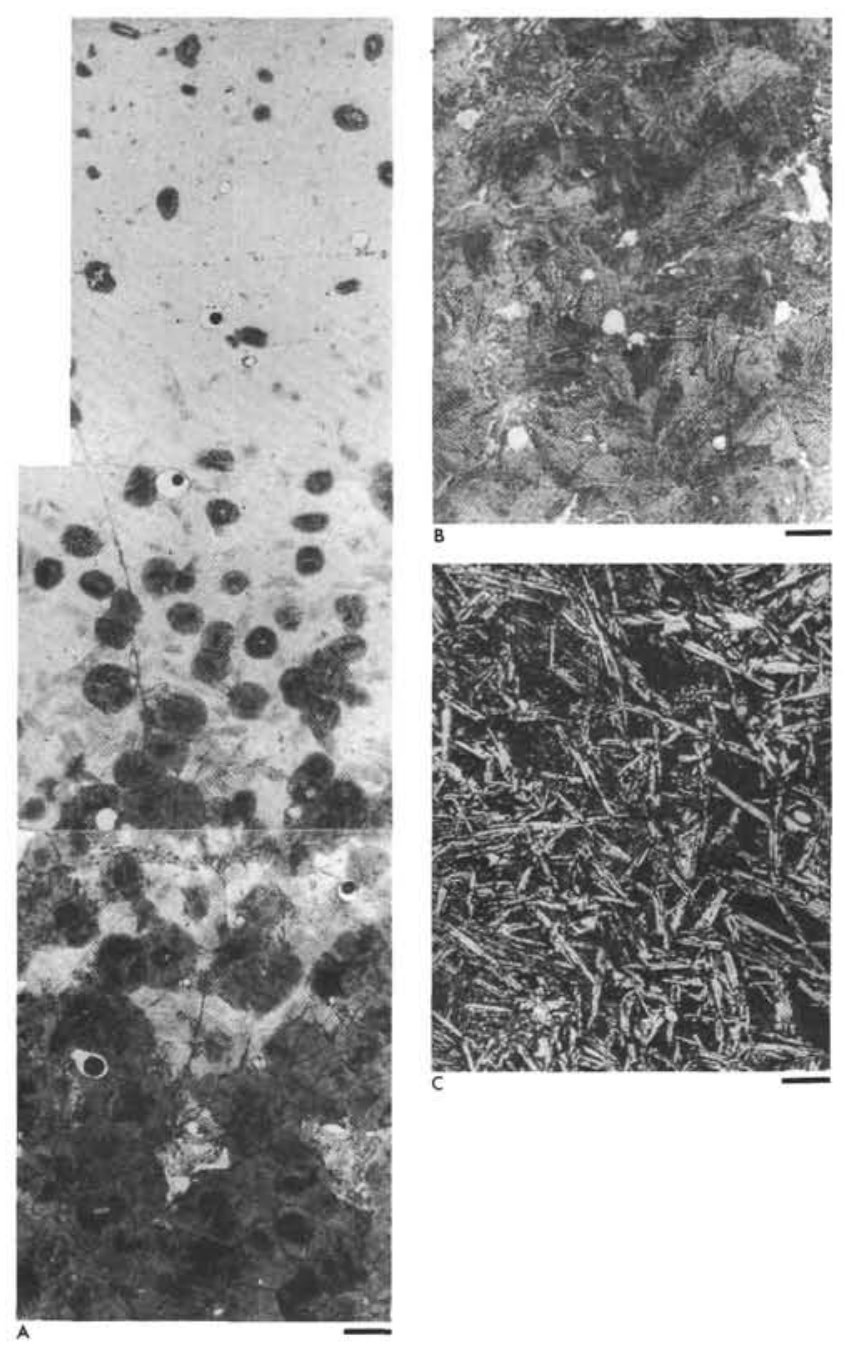

Figure 1. (A) Composite low magnification photomicrograph of Zones 2, 3, and 4 in Sample 7-1, 10-14 cm showing transition from isolated plagioclase spherulites (dark round patches) and olivine dendrites (light gray squares or rectangular patches) to coalesced olivine dendrites and partially coalesced plagioclase spherulites to fully coalesced plagioclase spherulites with distinct boundaries. Scale bar is $0.5 \mathrm{~mm}$. (B) Bow-tie plagioclase spherulites in Zone 5 of Sample 7-1, 10-14 cm. Note poorly defined boundaries between individual spherulites. Scale bar is $0.16 \mathrm{~mm}$. (C) Microlitic interior/Zone 6) of Sample 10-1, 64-69 cm. Scale bar is $0.16 \mathrm{~mm}$.

from this core to the margin of the crystal. The dendrites commonly occur with plagioclase in composite dendritespherulites. Almost all the plagioclase in this zone occurs in this way (best seen in ultra-thin polished thin sections) and many have non-dendritic olivine crystals at their center (Figures 3 and 4).

The plagioclase spherulites, in addition to the olivine, often have a skeletal plagioclase (or plagioclase and olivine, Figure 3) crystal in the center. This crystal becomes progressively more finely skeletal outward in the long direction [(parallel to $(010)$, Figure 4$)]$. Fibers also grow per-

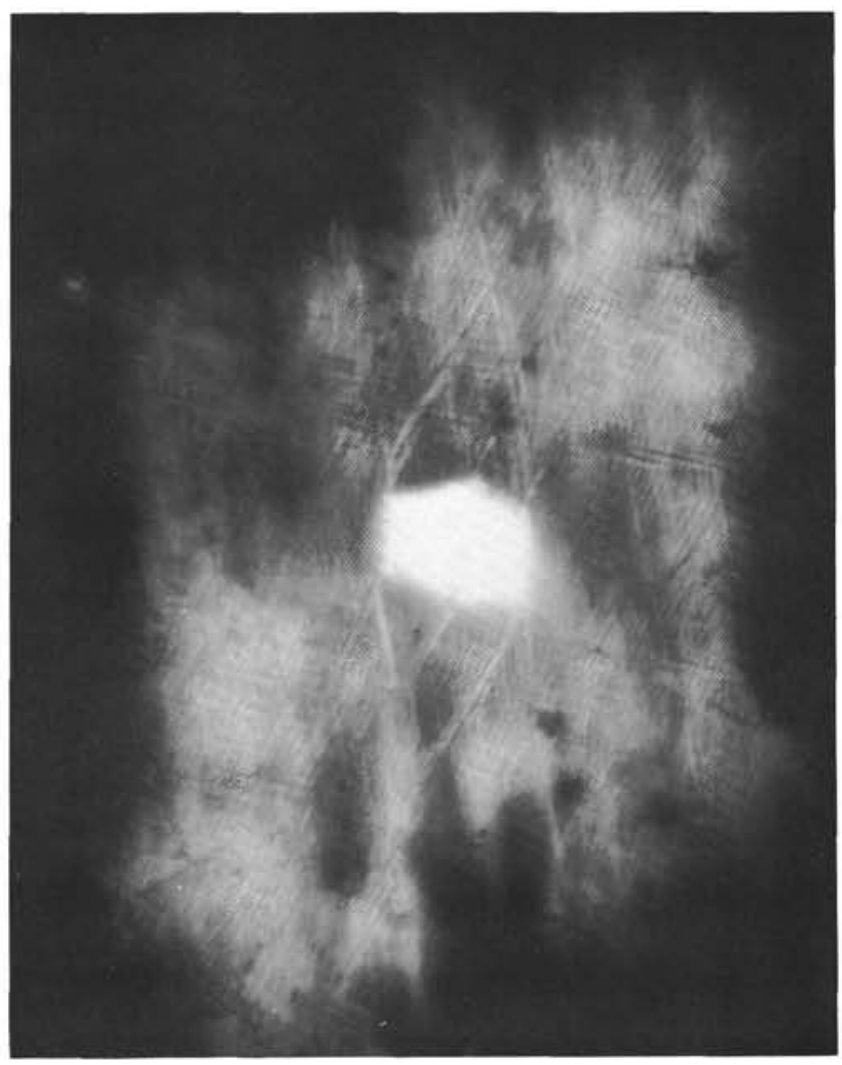

Figure 2. Isolated olivine dendrite from Zone 2 of Sample $10-1,10-14 \mathrm{~cm}$ showing non-dendritic center and progressively finer outward arms. Length of field is 0.08 $\mathrm{mm}$.

pendicular to (010) to give the entire aggregate an overall circular or oval shape in thin section. These fibers also become progressively finer outward. The central plagioclase laths and olivine crystals often occur together, and some spherulites contain clusters of several olivine and plagioclase grains. In Samples 11-2, 36-40 cm and 13-1, $89-93 \mathrm{~cm}$ the spherulites are concentrated in streaks parallel to the pillow margin. In the other samples there is a continual increase in abundance inward.

Pyroxene is not clearly identifiable in this zone, but may be the very fine high reflectivity material between the arms of the skeletal plagioclase crystals at the spherulite centers. Oxides are not present.

Zone 3 , which averages about $3 \mathrm{~mm}$ in thickness, is very similar to Zone 2 except that the olivine dendrites are almost completely coalesced (in Sample 10-1, 64-69 cm olivine coalescence is not complete) and the plagioclase spherulites are partially coalesced. The olivine dendrites are similar to those in Zone 2, but are larger, up to $0.5 \mathrm{~mm}$ in diameter. The plagioclase spherulites are also similar to those in Zone 2 and are also larger, up to $0.75 \mathrm{~mm}$ in diameter. As in Zone 2 , pyroxene cannot be positively identified, but may be the high reflectivity material between the arms of skeletal plagioclase crystals. Again, oxides are not present.

Zone 3 grades into Zone 4 , which averages about $6 \mathrm{~mm}$ in thickness, with the complete coalescence of the plagioclase spherulites and elimination of olivine dendrites between. 


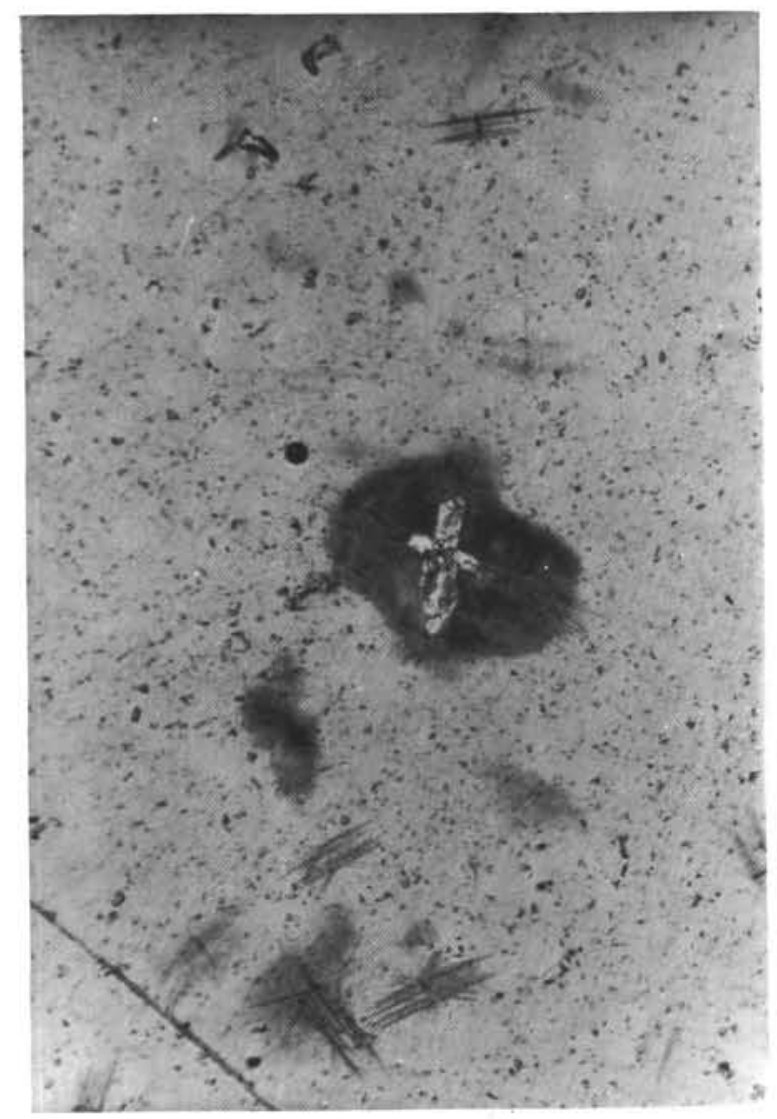

Figure 3. Isolated plagioclase spherulite from Zone 2 of Sample 7-1, 10-14 cm with olivine and plagioclase crystals at the spherulite center and dendritic olivine extending beyond the spherulite boundary. Note the many small olivine dendrites. Length of field is $0.8 \mathrm{~mm}$.

For the most part the spherulites are similar to those closer to the pillow margin, but are larger, up to $0.8 \mathrm{~mm}$ in diameter. The olivine in this zone occurs as skeletal crystals 0.05 to 0.13 $\mathrm{mm}$ in diameter, as dendrites within the plagioclase spherulites similar to those in the outer zoness (Figure 5), and especially in the inner part of the zone, as skeletal, lanternshaped, crystals up to $0.5 \mathrm{~mm}$ long. Again, the dendrites and their connection to the central non-dendritic olivine crystal are best seen in ultra-thin polished thin sections. In some samples the olivine appears to be less abundant in the inner part of the zone. This occurs where the groundmass is altered and is apparently not a primary feature.

The plagioclase laths at the center of the spherulites in this zone (Figures 5 and 6) are similar to those in the outer zones, but are larger, up to $0.7 \mathrm{~mm}$ long.

Pyroxene is clearly visible in reflected light almost out to Zone 3 and occurs as crystals between and elongate parallel to the arms of plagioclase crystals in the spherulites. Oxide minerals are not visible.

Zone 4 grades into Zone 5, which averages about $20 \mathrm{~mm}$ thick, as the plagioclase spherulites become progressively less oval and more bow-tie shaped and as the boundaries between the spherulites become less distinct. The olivine in

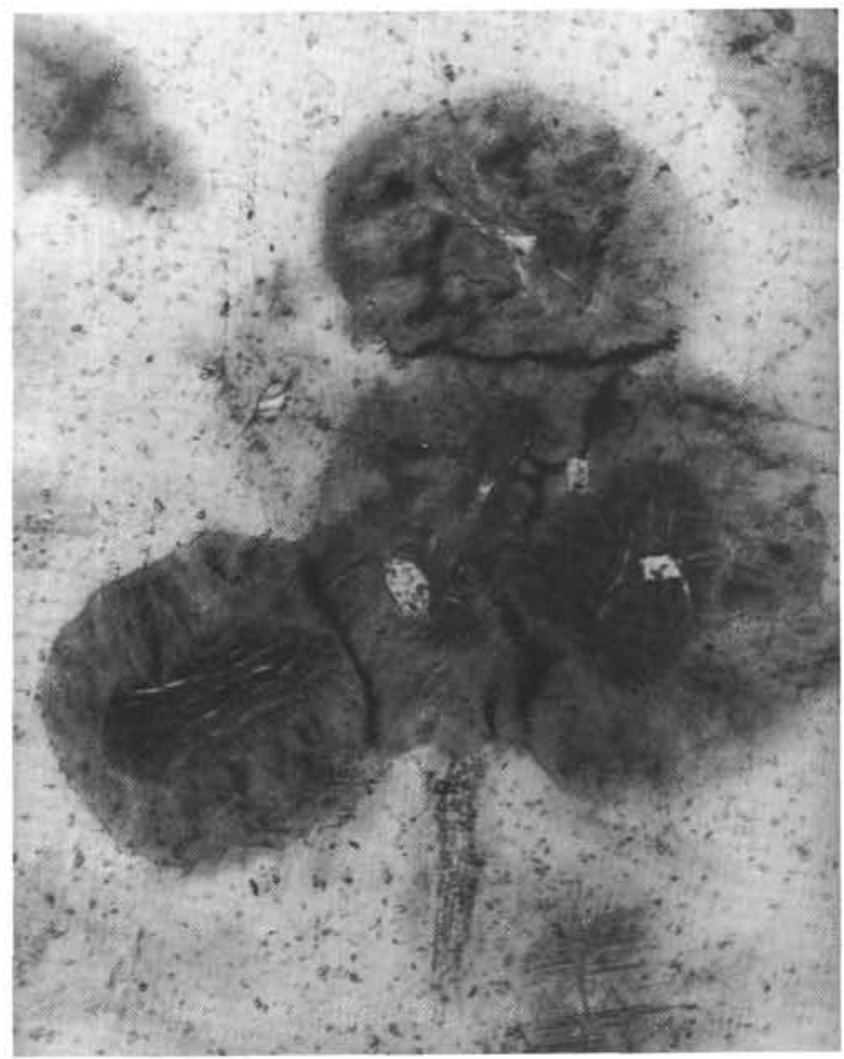

Figure 4. Cluster of plagioclase spherulites with plagioclase and olivine crystals at their center from the inner part of Zone 2 in Sample 7-1, 10-14 cm. Length of field is 0.6 $\mathrm{mm}$.

Zone 5 occurs as skeletal, sometimes lantern-shaped crystals from 0.04 to $0.8 \mathrm{~mm}$ long, and are very similar to those illustrated by Bryan (1972) from similar basalts. Some of these crystals occur in the center of bow-tie-shaped plagioclase spherulites, but many do not. In many samples the groundmass olivine in this zone is extensively altered.

The plagioclase in Zone 5 occurs as classic bow-tie spherulites (Lofgren, 1971) with very indistinct boundaries and elongate plagioclase at their centers (Figure 7) and also as patches of more microlitic crystals which become more common into the pillow. The bow-tie shape, rather than the spherical or oval shape, which occurs closer to the pillow margins, apparently develops because fibers do not grow at high angles to (010) of the central crystal. In Sample 8-1, $113-116 \mathrm{~cm}$ the bow-tie spherulites alternate with the coarse microlitic patches in bands parallel to the pillow margin. This is one of the samples in which plagioclase spherulites occur in bands in Zone 2 . In all samples the average grain size increases dramatically from the outside of the zone inwards.

Pyroxene in this zone occurs between and elongated parallel to the arms of plagioclase crystals as in Zone 4 and also, especially in the inner part of the zone, as separate dendritic crystals between plagioclase crystals in the microlitic patches. The pyroxene dendrites never grow large enough to have the complete fan-shaped morphology illustrated by Bryan (1972), but seem to be restricted to small 


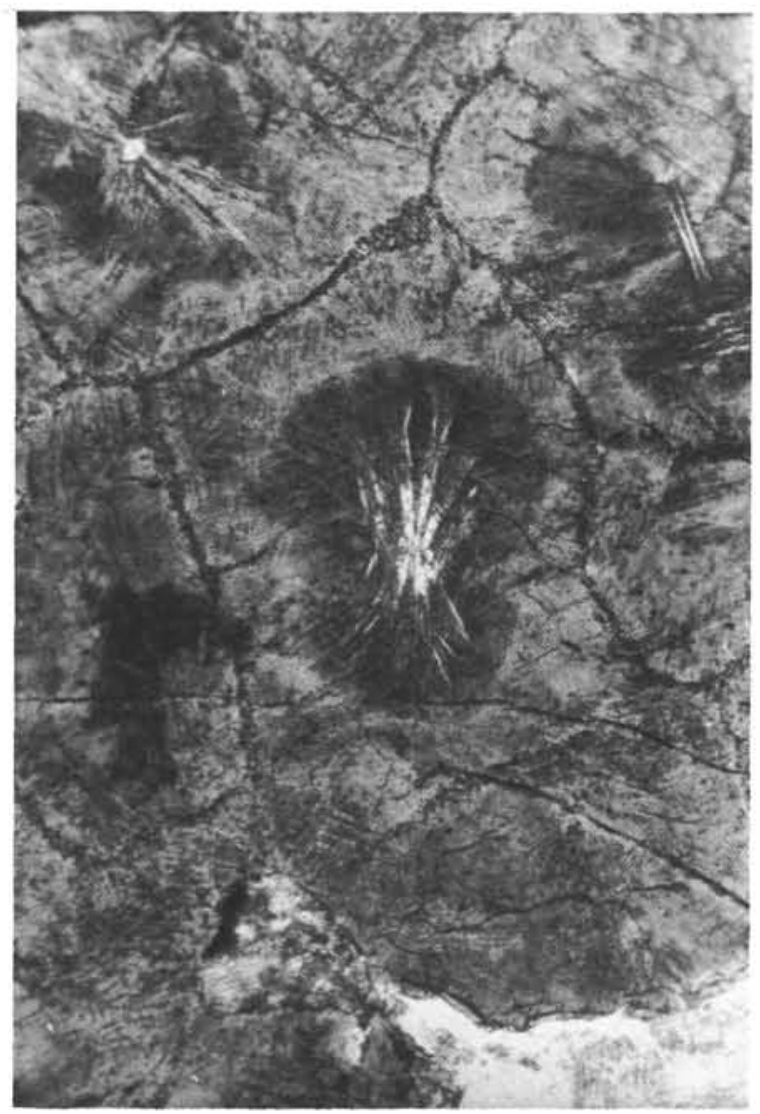

Figure 5. Coalesced plagioclase spherulites from Zone 4 of Sample 7-1, 10-14 cm showing central plagioclase skeleton, polygonal shape, and well-defined spherulite boundaries. Note parallel lines of olivine dendrites in the spherulites. Length of field is 0.8 $\mathrm{mm}$.

patches between plagioclase laths. In addition, there appears to be uncrystallized glass remaining between the arms of the pyroxene dendrites.

The opaque minerals in Zone 5 are skeletal titanomagnetite (N. Petersen, personal communication) up to $0.002 \mathrm{~mm}$ across.

Zone 5 grades into Zone 6 as the microlitic plagioclase takes over from the bow-tie spherulites. Although no continuous samples from pillow margin to interior are available for this type of pillow, the coarsest samples of sparsely phyric basalt recovered on Leg 46 have a coarse Zone 6 texture, and it appears that Zone 6 extends to the center of the pillows. Olivine in Zone 6 is similar to that in Zone 5 and is severely altered in many samples.

Plagioclase occurs as skeletal laths (Figure 8) up to 1.0 mm long, although most are considerably shorter. Many of the laths appear to be independent of each other, although some seem to have grown from central points with a very open bow-tie habit. The pyroxenes and opaques are similar to those in Zone 5 but are somewhat larger.

In those pillows where significant groundmass olivine has not grown (Table 1), six zones can also be defined. These zones are in many ways similar to those in the groundmass-olivine-rich pillows, although the zone thickness and grain sizes are considerably less than in the other

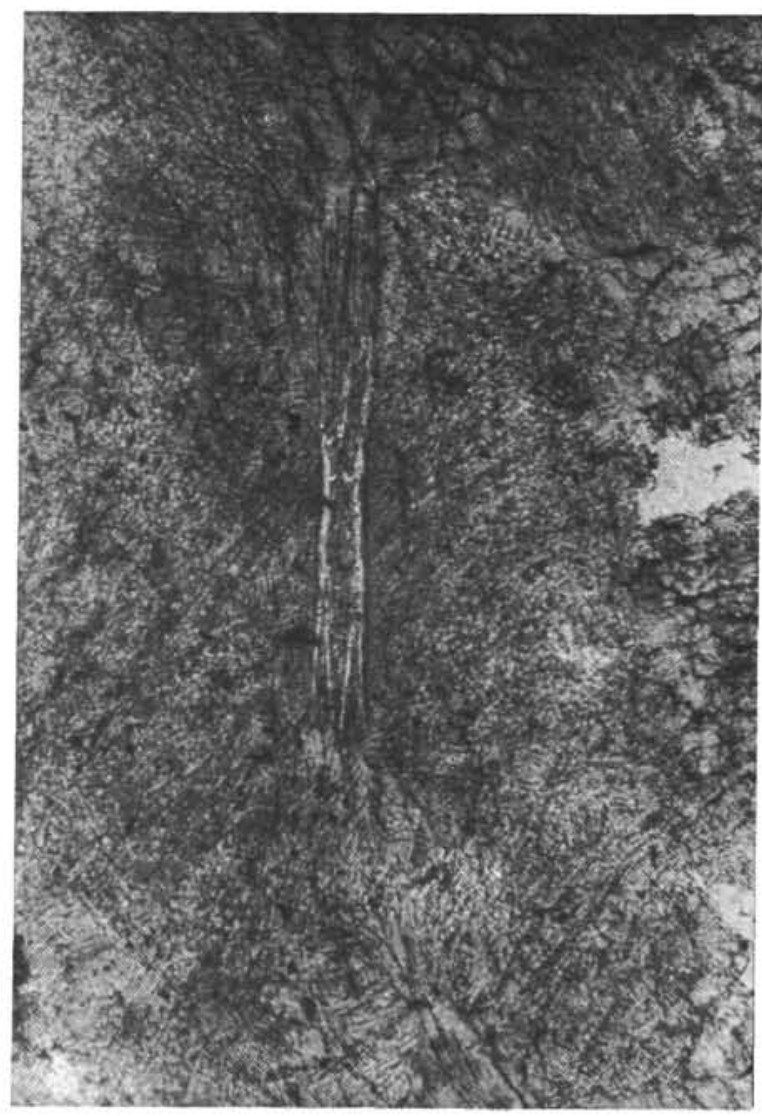

Figure 6. Plagioclase lath at a spherulite center which becomes progressively more finely skeletal and eventually breaks down into the spherulite (Zone 4 of Sample 7-1, 10-14 cm). Length of field is 0.3 $\mathrm{mm}$.

pillow type. From the pillow margin inward these zones are (1) glass; (2) glass with isolated plagioclase spherulites and a few olivine dendrites; (3) partially coalesced plagioclase spherulites with a few olivine dendrites; (4) fully coalesced plagioclase spherulites with well-defined boundaries; (5) plagioclase spherulites with a bow-tie habit and poorly defined boundaries; (6) microlitic plagioclase. Figures 9 and 10 illustrate the variations observed in the complete pillow in Core 20, Section 1.

Zone 1, the glass zone, does not occur in all samples and apparently has been lost during cooling or drilling. In addition to phenocrysts, the crystals in Zone 1 are skeletal to euhedral plagioclase and olivine up to $0.03 \mathrm{~mm}$ long which apparently grew before final crystallization. No spherulitic or dendritic development can be seen on either phase. As in the other pillow type, sulfide blebs a few $\mu \mathrm{m}$ across occur in this and all other zones.

Zone 2, the isolated plagioclase spherulite zone, averages about $2 \mathrm{~mm}$ in thickness. It contains only a few isolated olivine dendrites similar to those in the other pillow type. The plagioclase spherulites are only rarely associated with olivine and usually have only a skeletal plagioclase lath at their center. A very few of the larger ones have a cluster of plagioclase and olivine in the center. The diameter of the spherulites is less than in the other pillow type, ranging from 0.05 to $0.2 \mathrm{~mm}$. The few olivine dendrites are also 


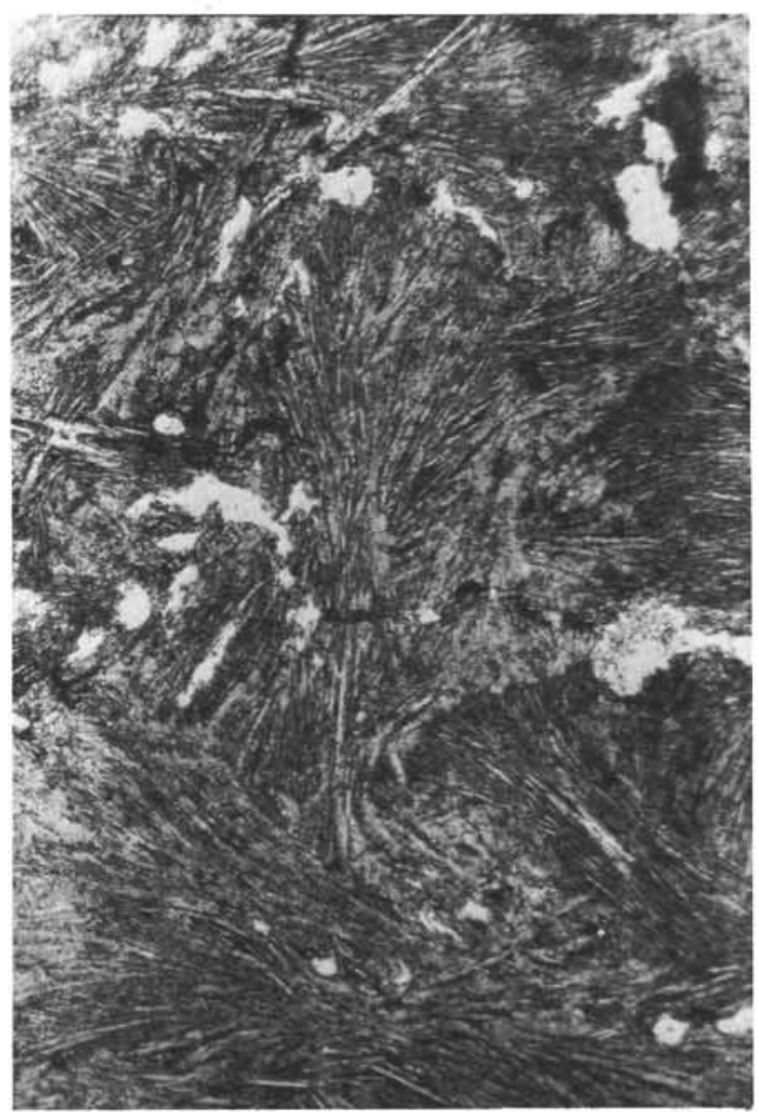

Figure 7. Bow-tie spherulites of Zone 5, Sample 7-1, $10-14 \mathrm{~cm}$ showing poorly defined spherulite boundaries and lack of fiber growth at high angles to (010). Length of field is $0.8 \mathrm{~mm}$.

smaller. The size of the fibers in the spherulites decreases from the center to the margin of the spherulites, and fiber growth takes place both at high angles to and near (010). Figure 11 presents SEM photographs illustrating the decrease in fiber width. No pyroxene can be identified positively, but it may occur between the arms of the skeletal plagioclases in the spherulite centers. No oxides are present.

Zone 3 , the zone of partially coalesced plagioclase spherulites is about $2 \mathrm{~mm}$ thick and is overall very similar to Zone 3 in the olivine-rich pillows, but with much less olivine and a smaller grain size. What olivine is present occurs as dendrites about $0.1 \mathrm{~mm}$ across, although in Sample 5-1, 63-167 cm it occurs as skeletal lantern-shaped crystals about $0.2 \mathrm{~mm}$ long. The plagioclase spherulites range up to $0.35 \mathrm{~mm}$ in diameter and are mostly oval in thin section. Many have a skeletal plagioclase lath at the center. Once again pyroxene cannot be positively identified but may be present, and oxides are not observed.

Zone 3 grades into Zone 4 , which is between 1.5 and 2.5 mm thick, as the plagioclase spherulites become fully coalesced. The polygonal boundaries between the spherulites in Zone 4 are well defined, but the spherulites are similar to those in Zones 2 and 3 and range up to $0.4 \mathrm{~mm}$ across. The skeletal plagioclase laths at the spherulite centers are also larger. What little groundmass olivine is present occurs as equant anhedral crystals or as lantern chain skeletons. For both plagioclase and olivine the grain size

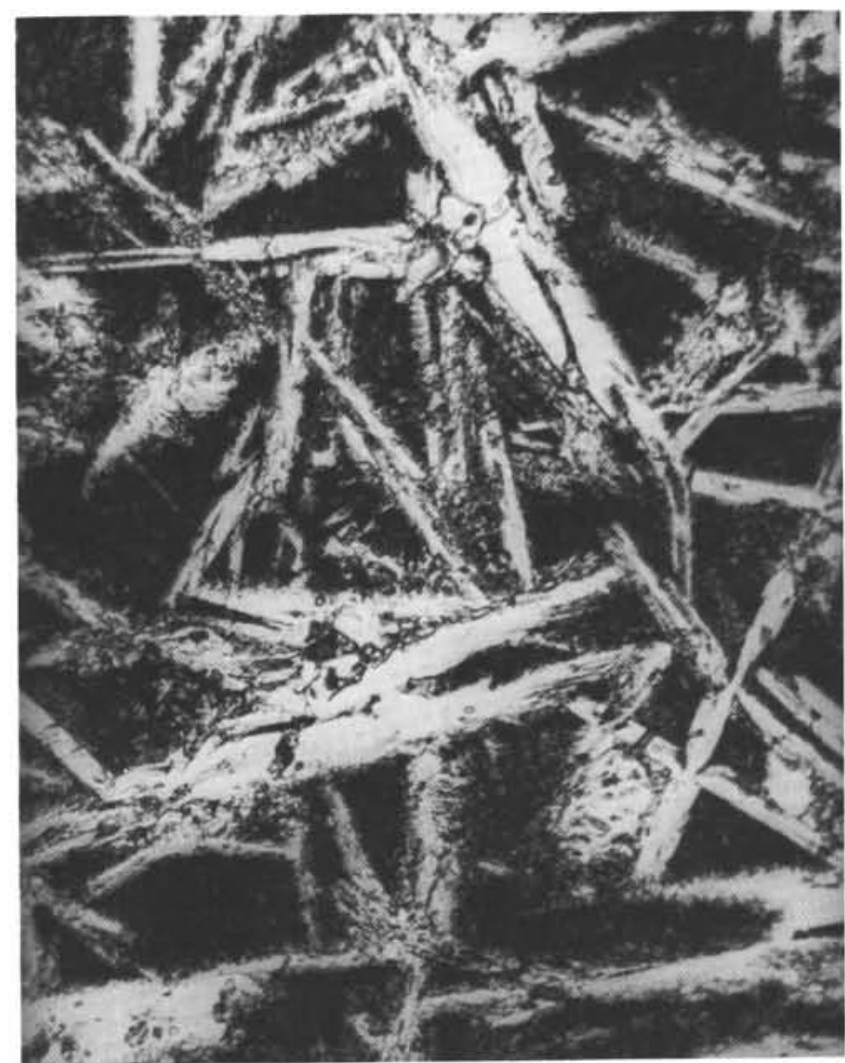

Figure 8. Skeletal microlites of plagioclase from Zone 6 of Sample 10-1, $6469 \mathrm{~cm}$. Length of field is $0.45 \mathrm{~mm}$.

increases inward. Pyroxene is not identifiable but is probably present between the arms of the plagioclase skeletons. Titanomagnetite is not clearly identifiable.

Zone 4 grades into Zone 5 , which is about $4 \mathrm{~mm}$ thick, as the boundaries between the plagioclase spherulites become less distinct and as the spherulites become more bow-tie shaped. As in the groundmass-olivine-rich pillows the bow-tie morphology appears to be due to the lack of fiber growth at high angles to (010) of the central plagioclase crystal.

The groundmass olivine in this zone is very inconspicuous and is altered in some samples. In others it occurs as lantern- and chain-shaped skeletons. Pyroxene occurs as crystals between and elongated parallel to the arms of plagioclase. A few 1- to $3-\mu \mathrm{m}$ titanomagnetite crystals are also present.

Zone 6 extends from where individual plagioclase laths become prominent to the pillow center. Near the boundary with Zone 5 the plagioclase occurs as open bow-tie spherulites and skeletal laths. Inward the spherulites disappear and the texture is dominated by individual skeletal plagioclase laths up to $0.7 \mathrm{~mm}$ long, although most are smaller. In many samples the olivine is altered.

In Zone 6 , near the boundary with Zone 5, pyroxene occurs elongate parallel to and between arms of skeletal plagioclase laths. Inward it occurs progressively more commonly as fan-shaped dendrites between the plagioclase laths. As in the other pillow type, the pyroxene does not grow large enough to exhibit the full fan-shaped morphology shown by Bryan (1972). 

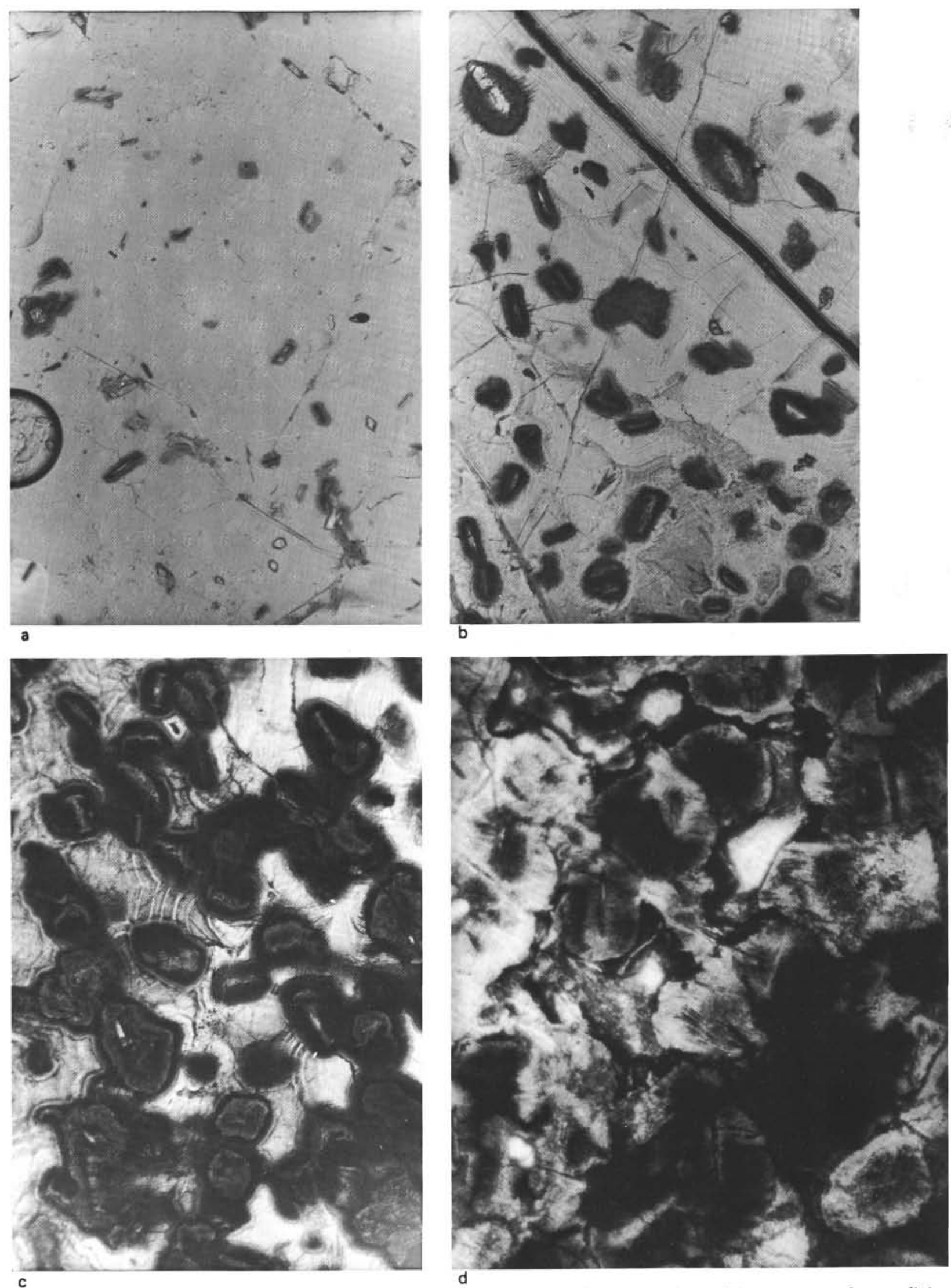

Figure 9. Photomicrographs of Sample 20-1, 36-80 cm showing textural variation inward into a groundmass-olivine-poor pillow. All fields except (D) are $3.1 \mathrm{~mm}$ long. (A) Zone 2 - note small olivine and plagioclase crystals with some plagioclase spherulite development. (B) Isolated plagioclase spherulites of the central part of Zone 2. Lines in glass are palagonite. (C) Partially coalesced plagioclase spherulites of Zone 3. Glass is palagonitized. (D) Fully coalesced plagioclase spherulites of Zone 4. Length of field is $1.2 \mathrm{~mm}$. 

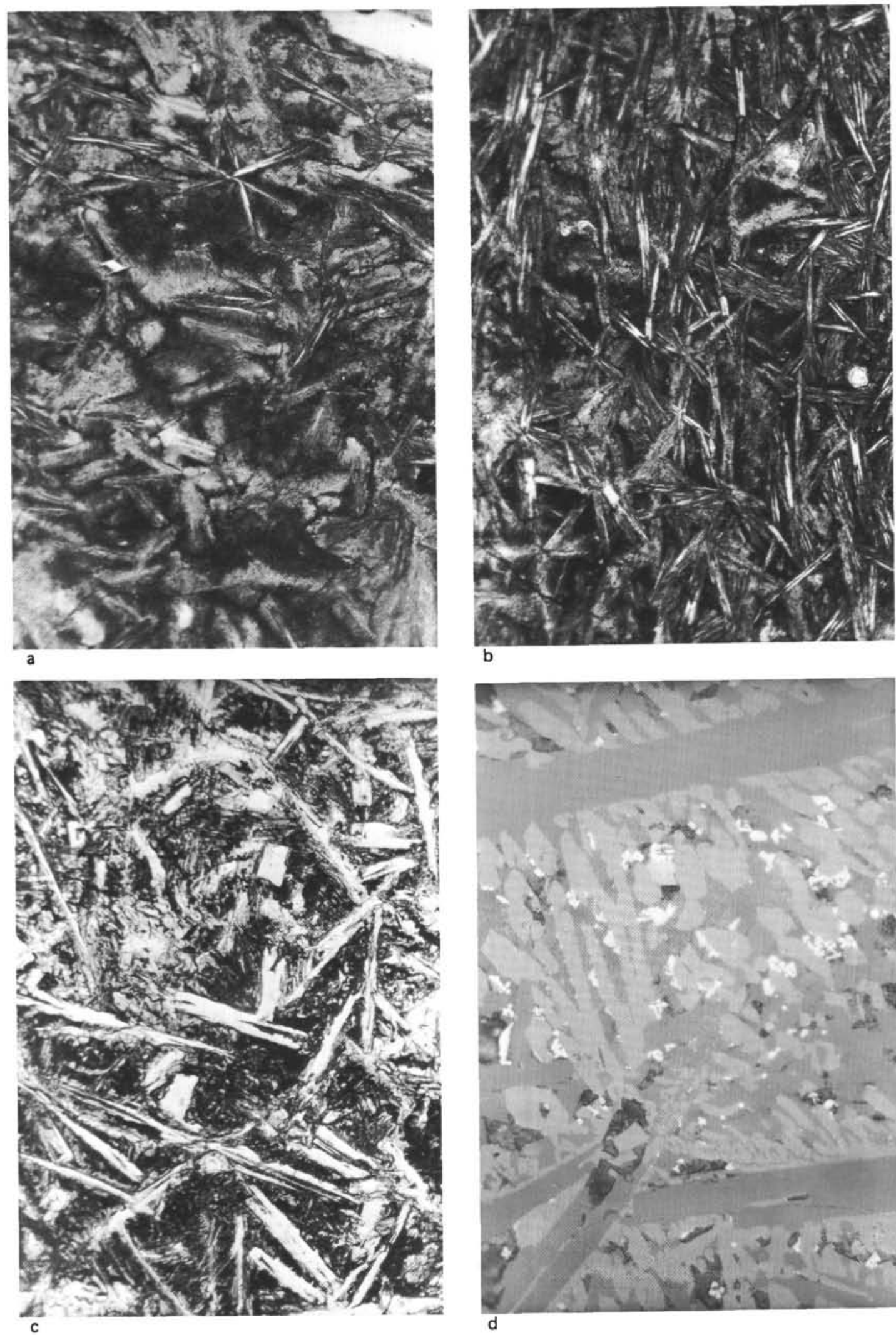

b

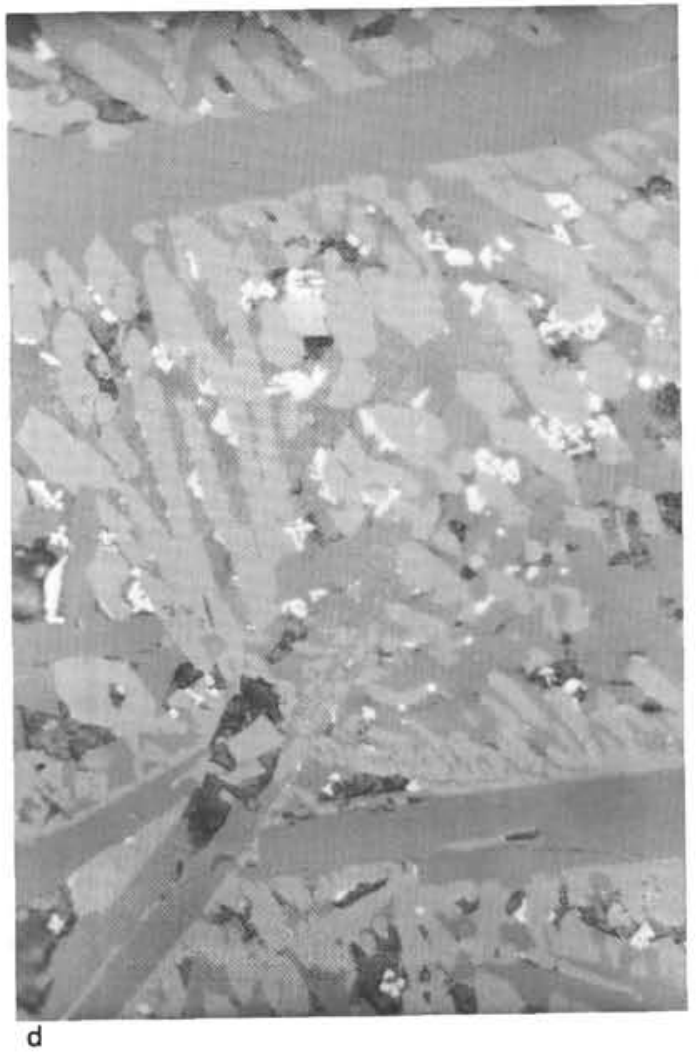

Figure 10. Photomicrographs of Sample 20-1, 36-80 cm showing textural variation into a groundmass-olivine-poor pillow. (A) Bow-tie spherulites of Zone 5 showing poorly defined boundaries. Length of field is $0.8 \mathrm{~mm}$. (B) Outer portion of Zone 6 showing plagioclase microlites and bow-tie spherulites. Length of field is $0.3 \mathrm{~mm}$. (C) Coarse-grained central part of Zone 6 showing large skeletal plagioclase laths with dendritic clinopyroxene between. Length of field is $0.8 \mathrm{~mm}$. (D) Reflected light view of skeletal plagioclase (dark gray), residual glass (medium gray), dendritic clinopyroxene (light gray), and skeletal titanomagnetite and round sulfide blebs (white) from coarse central part of Zone 6. Length of field is $0.2 \mathrm{~mm}$. 


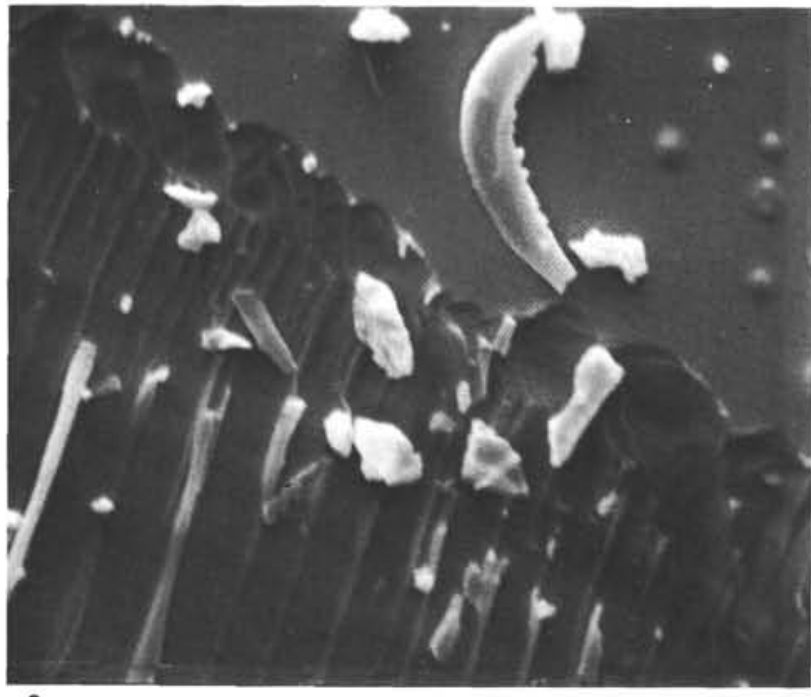

a

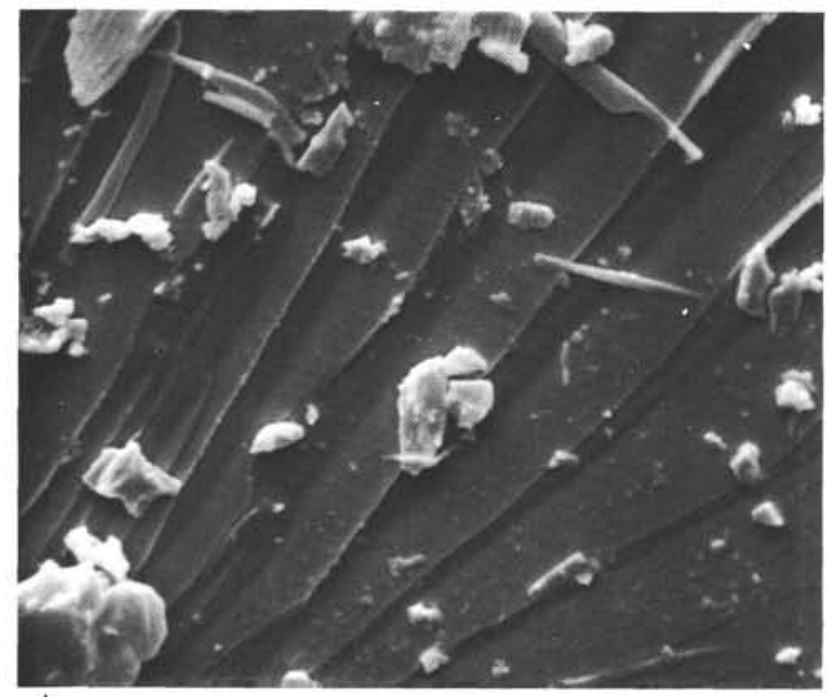

b

Figure 11. Scanning electron photograph of a fractured surface of Zone 2 in Sample 16-2, 125-133 cm showing the decrease in fiber diameter from near the center of a plagioclase spherulite (B) to the outside (A). This decrease takes place by an increase in the number of fibers, which can be best seen at the very edge of the spherulite in (A). Note also the faceted morphology of the fiber tips. (The rounding is due to fracture in the glass, the smooth material.) Length of field is about $40 \mathrm{\mu m}$.

The skeletal titanomagnetite crystals are up to $0.015 \mathrm{~mm}$ across. The size of the titanomagnetite increases inward to the pillow center.

\section{MICROPROBE AND QUANTITATIVE PETROGRAPHIC DATA}

Many features of rocks have been correlated with cooling rate, undercooling, or distance from a surface of cooling. Among these are plagioclase composition (Donaldson et al., 1975) and spacing between the arms of skeletal, spherulitic, or dendritic crystals (Lofgren, 1971; Walker et al., 1976). In the Leg 46 pillow basalts it appears that skeleton or dendrite arm spacing is well correlated with position in a pillow, but that plagioclase composition is not.
Figure 12 presents mole per cent anorthite and weight per cent $\mathrm{FeO}^{*}$ in plagioclase from the complete pillow, Sample 20-1, 36-80 cm. Compositions were determined using the automated MAC electron microprobe at the California Institute of Technology. It is clear that no systematic relationship exists between either maximum An or minimum $\mathrm{FeO}^{*}$ and position. The grains selected for analysis were the largest groundmass grains visible, and should represent the conditions just as the groundmass began to crystallize (i.e., highest An content and lowest $\mathrm{FeO}^{*}$ content).

Figure 13 presents the largest spacing observed between the arms of skeletal plagioclase and dendritic pyroxene in the same pillow in Core 20. Because of the wide range of spacing observed at each point (due to a range in undercooling), only the largest is plotted. These are the earliest formed groundmass crystals and are the only grains of each phase characteristic of a given position in the pillow (Kirkpatrick, 1976). It is clear that both plagioclase and pyroxene spacing increase with increasing distance from the pillow margin (surface of cooling).
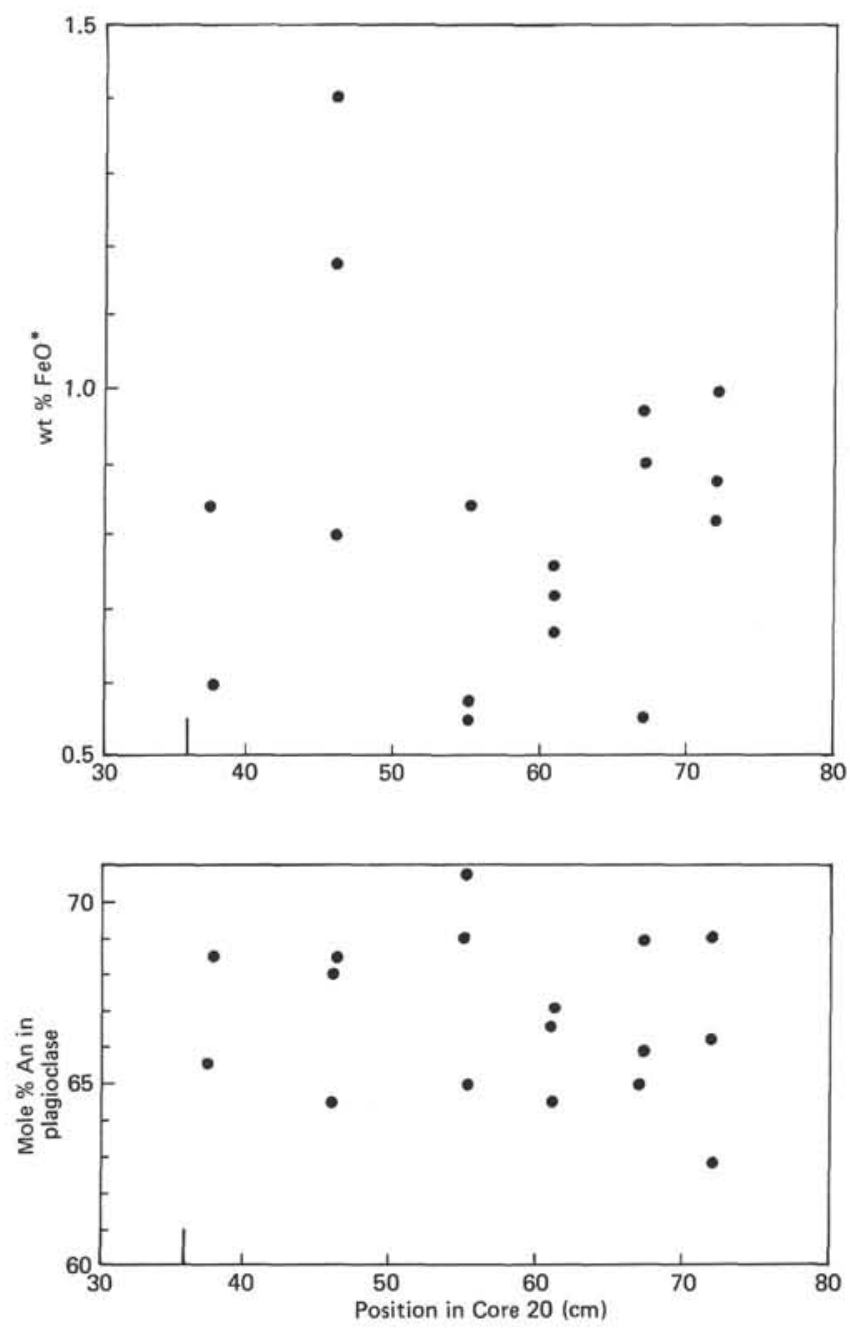

Figure 12. Mole percent anorthite and weight percent $\mathrm{FeO}^{*}$ in plagioclase versus position in Sample 20-1, $36-80 \mathrm{~cm}$ showing lack of correlation of maximum An content and minimum $\mathrm{FeO}$ * content with position in the pillow. Grains analyzed were the largest visible. 

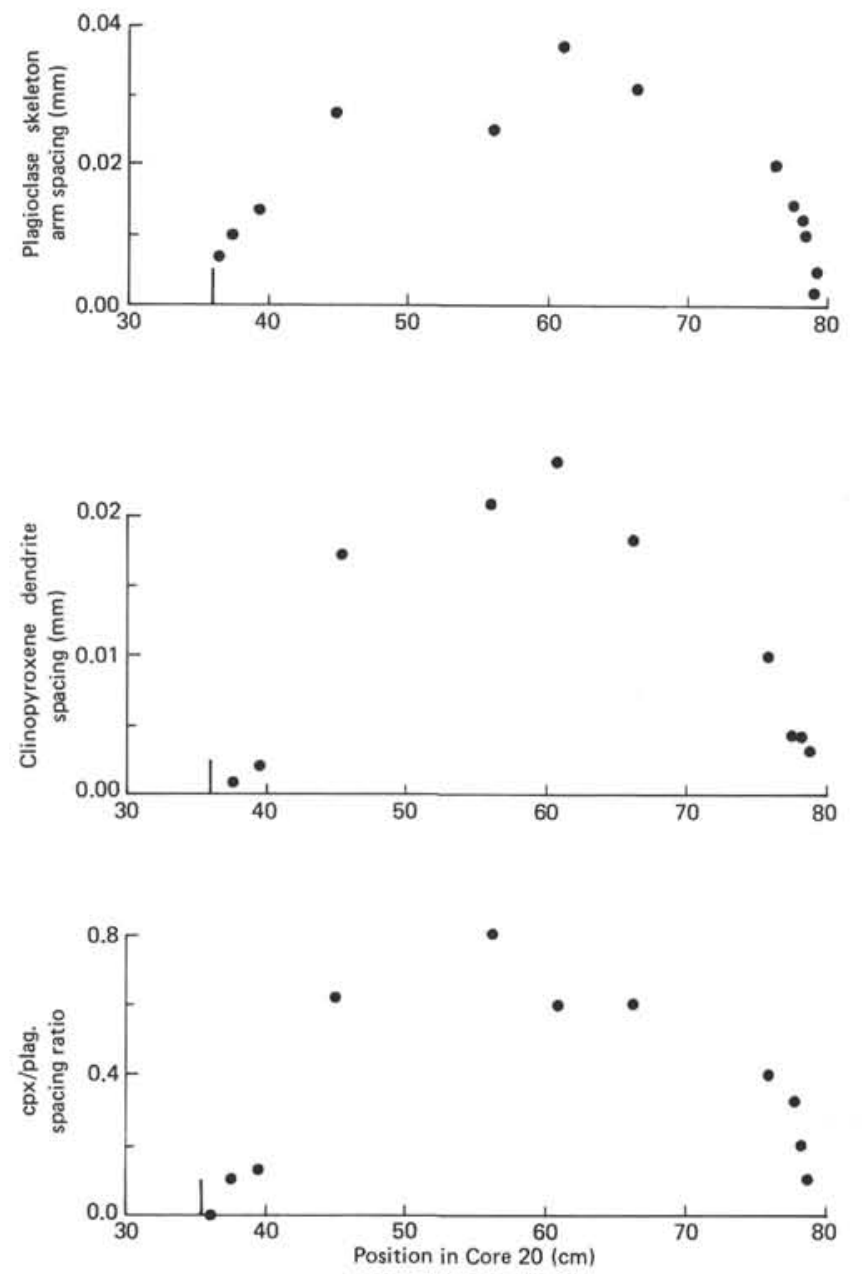

Figure 13. Maximum observed spacing between plagioclase skeleton and pyroxene dendrite arms versus position in Sample 20-1, 36-80 cm, the complete pillow, along with pyroxene/plagioclase spacing ratio. The increase of all three from the margin to the center is in good agreement with theoretical expectation.

Complete pillows of the groundmass-olivine-rich basalt were not recovered, but plagioclase spacing data for the thickest available sample-10-1, 64-69 $\mathrm{cm}$-are plotted in Figure 14 along with the data from the Core 20 pillow. From the margin to $4 \mathrm{~cm}$ in, the spacing for both types is the same, but at about $4 \mathrm{~cm}$ in, the spacing in the olivine-rich sample becomes significantly larger than in the olivine-poor sample. In fact, the spacing at $5 \mathrm{~cm}$ into the olivine-rich sample is larger than the largest spacing observed in the complete Core 20 pillow. This corresponds to the larger grain size in the olivine-rich basalt.

\section{THEORY}

Most of the petrographic features just described can be explained by various aspects of theory of crystallization kinetics. The theory of nucleation in condensed systems was developed by Turnbull and Fisher (1949) and has been reviewed by Christian (1965). The theory of crystal growth is well developed. Recent reviews include those of Uhlmann (1972) and Kirkpatrick (1975). The theory of nucleation and growth-controlled reactions was developed by Johnson and

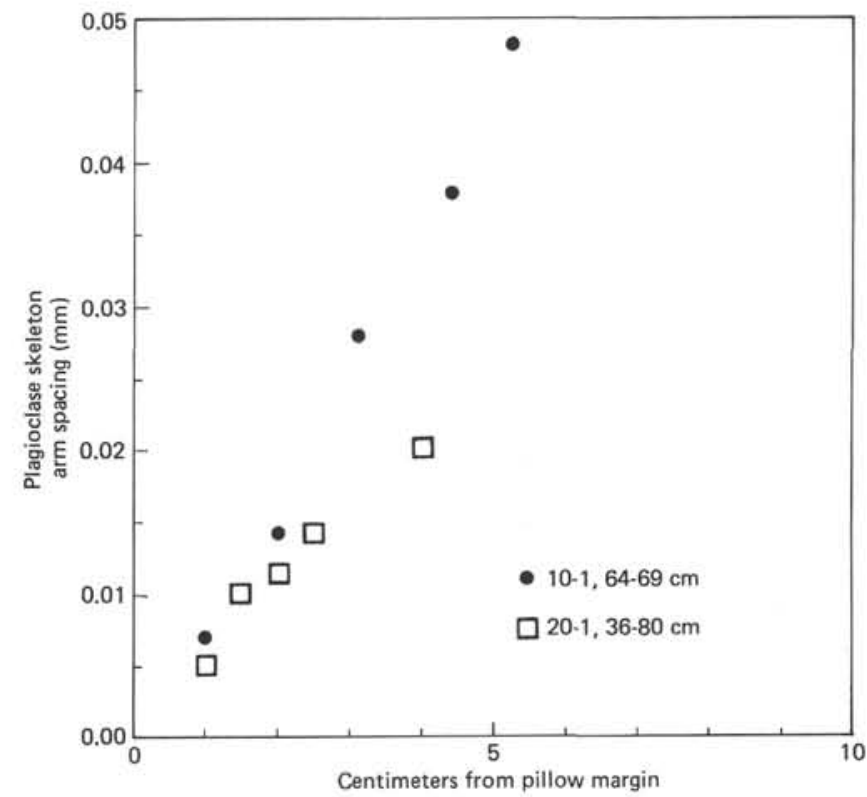

Figure 14. Maximum observed plagioclase skeleton arm spacing versus distance from the pillow margin of groundmass-olivine-rich and -poor pillows. The generally larger spacing for the olivine-rich pillow corresponds to a generally larger overall grain size.

Mehl (1939) and Avrami (1939, 1940, 1941) and has been applied to igneous systems by Kirkpatrick (1976). This section will briefly review the theoretical results necessary to interpret the features observed in the pillows.

The bulk crystallization kinetics of an igneous body can be described by a heat-flow equation including a term involving the rates of nucleation and growth of the crystalline phases (Kirkpatrick, 1976). The equation may be written

$$
\frac{d T}{d t}=k \nabla^{2} T+\frac{L_{v}}{\rho C_{p}} \frac{d V}{d t}
$$

where $T$ is temperature, $t$ is time, $k$ is the thermal diffusivity, $L v$ is the latent heat of crystallization per unit volume, $C p$ is the heat capacity, $\rho$ is the density, and $d V / d t$ is the rate of crystallization. In general

$$
\frac{d V}{d t}=f(\mathrm{I}, \mathrm{Y})
$$

where $I$ is the nucleation rate and $Y$ is the growth rate. Computer simulations using the Johnson-Mehl (1939) formulation for the rate of crystallization yield two important results: at a given fraction crystallized, the undercooling at which crystallization occurs decreases with increasing distance from a surface of cooling, and at a given distance from a surface of cooling, the undercooling increases continually as crystallization proceeds. The cooling rate, of course, is highest near the surface of cooling and decreases away from it.

Because of this, petrographic features which vary with undercooling, such as crystal morphology (Lofgren, 1974) or mineral compositions (Donaldson et al., 1975), should 
show systematic variations with respect to surfaces of cooling (pillow margins in our case).

The spacing between dendrite or skeleton arms is one good feature to examine because it depends to a large extent on the growth rate, which is highly dependent on undercooling. At small undercooling most silicate phases grow with euhedral morphology. At increasing undercooling, diffusion in the melt near the growing crystal becomes important in the growth process, and the euhedral morphology breaks down into a cellular morphology such as dendritic or skeletal. There appears to be systematic variation of the morphology with undercooling or cooling rate (Lofgren, 1974; Donaldson et al., 1975; Walker et al., 1976). The unifying feature of this variatioin seems to be that the spacing between the arms, no matter what the morphology, is related to the ratio of the rate controlling diffusion coefficient to the linear growth rate,

$$
x=C \frac{D}{Y}
$$

where $X$ is the spacing, $D$ is the diffusion coefficient, $Y$ is the growth rate, and $C$ is a constant involving compositions (Keith and Padden, 1963; Lofgren, 1971). With increasing undercooling the diffusion coefficient decreases but the growth rate increases for perhaps a hundred or two hundred degrees (Scherer et al., 1972; Kirkpatrick et al., 1976). Thus, in this undercooling range the spacing decreases rapidly with increasing undercooling. Keith and Padden (1963) have also shown that the spacing continues to decrease even at temperatures below the growth rate maximum.

In the Leg 46 pillows the variation in spherulite morphology with position may be explained by the way nucleation of the various crystalline phases takes place. Nucleation can occur in two ways, homogeneously, with the influence of an outside agent; or heterogeneously, on a pre-existing surface. In general, if an appropriate substrate is present, the rate of heterogeneous nucleation will be much higher than the rate of homogeneous nucleation. For both types, however, the rate is zero at the equilibrium temperature, increases to a maximum at an undercooling generally larger than the maximum in the growth rate, and then decreases (Fenn, 1976, presents related data for the alkali feldspar system).

\section{DISCUSSION}

From the petrographic descriptions given above it appears that there are three general kinds of variation in the pillows: variation at one place in a pillow, variation with position in a pillow, and variation between pillow types. Most of the variation within a pillow (either at a point or with position) can be explained by the theory just presented. The reasons for the differences between the pillow types are less clear.

The variations observed at one point in a pillow include the decreasing spacing between the arms of dendritic olivine or fibers in speherulitic plagioclase with distance from the center of the dendrite or spherulite. The theory of cellular crystallization just discussed and the experimental results in silicate systems (Lofgren, 1974; Walker et al., 1976) indicate that this continual decrease must be due to a continual decrease in undercooling as crystallization progressed. This is in good agreement with the predictions of the computer simulations using the theory of bulk crystallization kinetics (Kirkpatrick, 1976). Similarly, the observed increase in maximum plagioclase and pyroxene spacing with distance from the pillow margin must be due to the decreasing undercooling at which crystallization began with increasing distance from the margin. This, too, is in agreement with the predictions of the computer simulations.

The sequence of zones observed is also related to the way undercooling varies with cooling rate and therefore to the rates of nucleation and growth. Zone 1, the glassy, essentially groundmass-free zone, occurs because the temperature falls so rapidly through the maxima in the nucleation and growth rate curves that few crystals have time to grow. Zone 2, the zone of isolated spherulites and dendrites, occurs because the cooling rate there is such that just a few crystals can nucleate and those that do only have a short time to grow before the undercooling gets so large that the rate is imperceptible. Zone 3 is due to somewhat lower cooling rates (and therefore smaller undercoolings) than in Zone 2 . In the groundmass-olivine-rich pillows the olivine has had time to grow until it has coalesced and can grow no more, while the plagioclase has only partially coalesced in both pillow types. Zone 4 is due to yet slower cooling rates which allowed the plagioclase spherulites to coalesce fully.

The difference between Zones 4 and 5 is that the plagioclase spherulites in Zone 4 are polygonal in thin section and have distinct boundaries, while those in Zone 5 are bow-tie shaped and have indistinct boundaries. This difference is apparently due to the undercooling dependence of the nucleation rate of plagioclase fibers on the (010) surface of the central plagioclase lath. In Zone 4, undercooling apparently gets large enough so that significant heterogeneous nucleation can take place there before the spherulites coalesce, giving them their round or oval shape. In Zone 5, on the other hand, undercooling apparently does not get large enough to promote nucleation of the $(010)$ fibers before crystallization is complete. This leaves the spherulite with the bow-tie shape due to growth in and near the (010) plane. Because the spherulites are not growing uniformly in all directions, they grow into and through each other, yielding a more ragged boundary.

In Zone 6 the cooling rates are low enough to allow most of the plagioclase to grow as individual laths (a relatively small undercooling morphology) before the undercooling becomes large enough to promote spherulitic growth. The transition between Zones 5 and 6 , where both laths and spherulites are present, occurs where the cooling rate was such that some of the plagioclase could crystallize at small undercoolings as laths and the rest at larger undercoolings as spherulites.

The variation in pyroxene morphology is also related to the increasing undercooling with increasing cooling rate. In the outer zones, pyroxene occurs as grains elongate parallel to and between the arms of skeletal plagioclase laths. Apparently both phases were growing together in a cooperative fashion. This cooperative growth is a common phenomenon in many kinds of systems (Christian, 1965), and has been observed in programmed cooling experiments using lunar picritic basalt (Walker et al., 1976). Apparently plagioclase crystallization takes place at undercoolings large enough so 
that pyroxene can grow in the pyroxene-rich melt between the skeleton arms. Further in, mostly in Zone 6 and part of Zone 5 . the pyroxene occurs as separate dendritic crystals between the plagioclase grains. In this region the plagioclase must have crystallized at small enough undercoolings so that pyroxene could not grow simultaneously. When the temperature falls to the point where pyroxene begins to crystallize (not necessarily the equilibrium temperature, Walker et al., 1976), it is restricted to growing between the already-formed plagioclase laths.

The change in olivine morphology from dendritic near the pillow margin to skeletal in the center is also in agreement with the decreasing undercooling at increasing distance from the pillow margin. Donaldson et al. (1975) have shown that this change occurs in programmed cooling experiments with lunar pyroxene-phyric basalts as the cooling rate decreases.

The sequence of appearance of phases from the pillow margin inward is also a kinetic effect related to the cooling rates. Walker et al. (1976) examined the temperature of appearance of the crystalline phases in the lunar picritic basalt 12002 as a function of cooling rate and found that increasing cooling rate can progressively reduce the temperature of appearance of a phase and eventually suppresses its crystallization all together. This process affects the liquidus phase least (olivine for 12002), and the lowest temperature phases most, and can even reverse the sequence of phases from the equilibrium sequence.

This apparently is what happened in the pillows. At the pillow margin the cooling rate was so high that all phases were completely suppressed. The sequence in the groundmass-olivine-rich pillows is olivine and plagioclase in Zone 2, clinopyroxene in Zone 4, and titanomagnetite in Zone 5. In the groundmass-olivine-poor pillows the sequence is plagioclase and then olivine in Zone 2, and clinopyroxene and titanomagnetite in Zone 5 . In both pillow types, both clinopyroxene and titanomagnetite may appear farther out, but cannot be positively identified. Figure 15, comparable to fig. 2 of Walker et al. (1976), illustrates these relationships for the two pillow types. Ilmenite, which does crystallize under the more slowly cooled conditions of the Core 15 cooling unit (Leg 46 Shipboard Party, this volume) is suppressed even at the relatively low cooling rates in the pillow centers. These diagrams illustrate only the first appearance of the phases. The amounts present, as noted above, depend upon how much time was available for crystallization once they formed.

While most of the variation within a pillow can be understood in terms of the rates of the various processes which operated while crystallization was going on, the differences between the two pillow types is not as clear. The principal differences between the two types are that the olivine-poor pillows have less groundmass olivine, a smaller grain size and plagioclase spacing, and a more compressed zoning sequence with thinner zones. The glass compositions (the liquid from which the groundmass was growing) for the two pillow types are not greatly different; both have a few per cent normative olivine, along with normative plagioclase, augitic pyroxene, hypersthene, magnetite, and ilmenite (Flower et al., this volume). Composition is not, then, likely to be the cause. Neither is phenocryst content, since
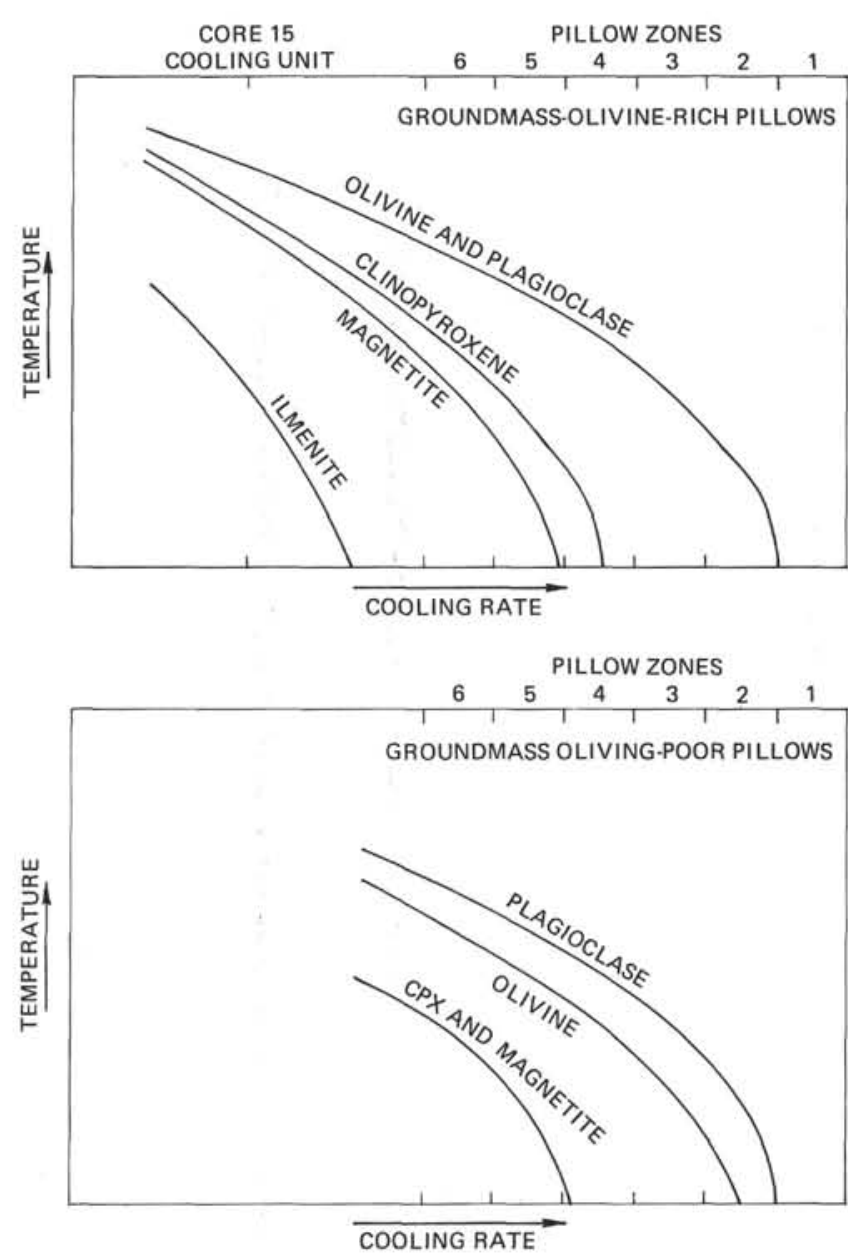

Figure 15. Schematic temperature-cooling rate diagrams for the two pillow types, illustrating the temperature of appearance of each phase in the various zones and the cooling rate which completely suppresses each phase. (See Walker et al., 1976, for a similar, but quantitative, diagram for lunar picrite 12002.)

olivine-poor pillows are both porphyritic and sparsely phyric. The difference in volatile content does not seem to be great either.

The difference may lie in the way the pillows were erupted and cooled, but this is difficult to test when the three-dimensional relationships cannot be seen. Phase equilibrium and programmed cooling experiments, including the effect of phenocryst content, may help.

\section{REFERENCES}

Avrami, M., 1939. Kinetics of phase change, I, J. Chem. Phys., v. 7, p. $1103-1112$.

, 1940. Kinetics of phase change, II, J. Chem. Phys., v. 8 , p. $212-224$.

, 1941. Granulation, phase change, and microstructure, J. Chem. Phys., v. 9, p. 177-184.

Bryan, W. B., 1972. Morphology of crystals in submarine basalts, J. Geophys. Res., v. 77, p. 5812-5819.

Christian, J. W., 1965. The theory of transformations in metals and alloys: New York (Pergamon). 
Donaldson, C. H., Usselman, T. M., Williams, R. J., and Lofgren, G. E., 1975. Experimental modeling of the cooling history of Apollo 12 olivine Basalt, Lunar Sci. Conf. Proc., 6th, p. 843-869.

Dowty, E., Keil, K., and Priuz, M., 1974. Lunar pyroxene-phyric basalts: crystallization under supercooled conditions, J. Petrol., v. 15 , p. $419-453$.

Fenn, P. M., 1976. The nucleation and growth of sodium-rich alkali feldspar from hydrous melts in the systems $\mathrm{NaAlSi}_{3} \mathrm{O}_{8}$ $\mathrm{KAlSi}_{3} \mathrm{O}_{8}-\mathrm{H}_{2} \mathrm{O}$ and $\mathrm{NaAlSi}_{3} \mathrm{O}_{8}-\mathrm{SiO}_{2}-\mathrm{H}_{2} \mathrm{O}$ (abstract), Prog. to 1976 Geol. Assoc. Canada Ann. Meeting, p. 65.

Johnson, W. A. and Mehl, R. F., 1939. Reaction kinetics in processes of nucleation and growth, Am. Inst. Mining Eng., Tech. Publ. 1089, p. 1-27.

Kay, R., Hubbard, N. J., and Gast, P. W., 1970. Chemical characteristics and origin of ocean ridge volcanic rocks, $J$. Geophys. Res., v. 75, p. 1585-1614.

Keith, H. D. and Padden, F. J., 1963. A phenomenological theory of spherulitic crystallization, J. Appl. Phys., v. 34, p. 24092421.

Kirkpatrick, R. J., 1975. Crystal growth from the melt: A review, Am. Mineralogist, v. 60, p. 798-814.

,- 1976 . Towards a kinetic model for the crystallization of magma bodies, J. Geophys. Res., v. 81, p. 2565-2571.
Lofgren, G., 1971. Spherulitic textures in glassy and crystalline rocks, J. Geophys. Res., v. 76, p. 5635-5648.

, 1974. An experimental study of plagioclase morphology, Am. J. Sci., v. 273, p. 243-273.

Lofgren, G., Donaldson, C. H., Williams, R. J., Mullins, O., and Usselman, T. M., 1975. Experimentally reproduced textures and mineral chemistry of Appollo 15 quartz normative basalts, Lunar Sci. Conf. Proc., 6th, p. 549-567.

Scherer, G., Hopper, R. W., and Uhlmann, D. R., 1972. Crystallization behavior and glass formation of selected lunar compositions, Lunar Sci. Conf. Proc., 3rd, p. 2627-2637.

Turnbull, D. and Fischer, J. C., 1949. Rates of Nucleation in condensed systems, J. Chem. Phys., v. 17, p. 71-73.

Uhlmann, D. R., 1972. Crystal growth in glass forming systems-A review. In Hench, L. L. and Freiman, S. W. (Eds.), Advances in nucleation and crystallization in glasses: Cleveland, (Am. Ceram. Soc.), Spec. Pub. 5.

Walker, D., Kirkpatrick, R. J., Longhi, J., and Hays, J. F., 1976. Crystallization history of lunar picritic basalt sample 12002: Phase-equilibria and cooling rate studies; Geol. Soc. Am. Bull., v. 87, p. $646-656$. 